\title{
Emotion and music: The Ethiopian lyre bagana
}

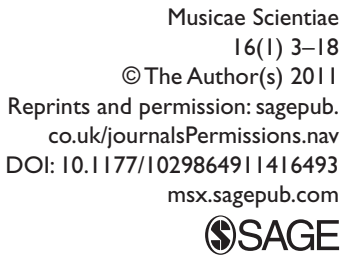

Musicae Scientiae

The Author(s) 2011

rints and permission: sagepub. co.uk/journalsPermissions.nav msx.sagepub.com

(S)AGE

\section{Stéphanie Weisser}

Museum of Musical Instruments, Belgium

\begin{abstract}
The bagana is a paraliturgical lyre played by the Christian Amhara of Ethiopia. It is used to perform spiritual music. Bagana is an intimate instrument, accompanied by the singing voice only. It has a special role in Christian Amhara music, as its myth of origin closely connects it to God, the biblical King David and King Menelik I. It is reputed to be very powerful and its performances arouse intense reactions in both players and listeners. Some of these reactions were observed directly (immediate calming, tears, overwhelmed faces). Inner reactions to bagana were investigated by means of 108 statements collected from 32 participants (from virtuoso players to simple listeners) during interviews or discussion. Statements were classified by using the Strong Experiences related to Music (SEM) descriptive system (Gabrielsson \& Lindström Wik, 2003). Results show that the inner reactions bagana elicits are varied (statements fall into six of the seven categories of the SEM descriptive system) but a majority of the statements can be classified into the Feelings/Emotions (5) and Existential and Transcendental (6) categories. The least commonly admitted reactions fall into the Physical Reactions and Behaviours (2) and the Perception (3) categories. These results are discussed in detail and confronted with the direct observations. The utility and difficulties of the SEM descriptive system in ethnomusicological contexts are also discussed.
\end{abstract}

\section{Keywords}

emotion, ethnomusicology, music, SEM descriptive system

\section{Introduction}

Now divine aire, now is his soule ravisht, is it not strange that sheepes guts should hale soules out of mens bodies?

(William Shakespeare, Much Ado about Nothing, act 2, scene 3)

One of the most common sayings about music is that it can elicit inner reactions. This conception seems to be shared by numerous cultures around the globe (Becker, 2004; Rouget, 1990): Alan P. Merriam (1964), listing ten functions of music (pp. 219-227), placed expression of emotion among the first ones. Nevertheless, the exact processes by which music evokes inner reactions and the exact nature of these reactions are still controversial. Moreover, the question 
is rarely investigated in non-Western musical contexts. When an ethnomusicologist wants to look into the question of the inner reactions non-Western music elicits within its culture, he or she faces major conceptual difficulties. Few ethnomusicological works explore this question in detail and when they do, they usually explain the inner reactions only in terms of context and belief system of the musical performance, even though several ethnomusicologists are not satisfied with such an explanation(Aubert, 2005,p. 211;Nattiez, 2005,p.971).Ethnomusicologists lack a methodological frame within which to analyse, quantify and describe with accuracy both the nature of the musical emotions in the context they study, as well as the process whereby these repertoires elicit emotions within that context. On the other hand, experimental psychologists do try to formalize the production rules of inner reactions, but they mostly (and often implicitly) focus on listeners and stimuli belonging to the western cultural area (Scherer \& Zentner, 2001, p. 361). Nevertheless, ethnomusicologists can benefit from some methodological models originally carried out in a Western context, namely those investigating the nature of the music-induced emotion itself, whose importance has been noted (Scherer \& Zentner, 2001, p. 362; Zentner, Grandjean, \& Scherer, 2008, pp. 494-495).

The aim of this paper is to present the results of an empirical investigation, from an ethnomusicologist's point of view, into the nature of the inner reactions aroused by the Ethiopian lyre bagana in both players and listeners, using the detailed descriptive system elaborated by Gabrielsson (Gabrielsson, 2001; Gabrielsson \& Lindström Wik, 2003), in the light of direct observations.

\section{Conceptual framework}

Inner reactions are difficult to define and to investigate. According to Damasio (2003, p. 53), a competent stimulus induces a collection of chemical and neuronal responses forming a distinctive pattern called an emotion-proper. This emotion-proper results in a temporary change of the state of the body and in the brain structures. The mental representation of this change is called a feeling. Thus the concept of feeling encompasses both physiological responses theoretically objective and observable - to an internal or external stimulus and the physical and mental changes experienced, deemed subjective. In the field of ethnomusicology, feeling, as a complex cognitive culturally inflected interpretation of an emotion (Damasio quoted in Becker, 2001, p. 145) is the most often investigated for obvious technical reasons. Measuring changes of physiological factors (increased heartbeat, blood pressure, respiration rate and muscle tension, and decreased skin temperature, cf. Rickard, 2004, p. 372) is difficult to achieve in the field, especially during in-context performances and in areas with limited access to power supply. Inner non-physiological reactions to music are also difficult to investigate. Furthermore, the reliability of the available sources of information (observation of the behaviour, self-reports) prove problematic. Behaviour can be determined by other factors than inner reactions (Ortony, Clore, \& Collins, 1988 , p. 8-12) and self-reports, like any discourse about music, are specific symbolic forms to be investigated as such (Nattiez, 1981).

Nevertheless, the use of carefully analysed self-reports in investigations concerning inner reactions to music is worthwhile. A detailed study on intense reactions to music has been developed by Gabrielsson (Gabrielsson, 2001; Gabrielsson \& Lindström Wik, 2003) in order to understand how people may be deeply affected by music and to obtain a precise description of the components of strong experiences related to music. Strong Experiences related to Music (SEM) have been investigated by means of free descriptions and have led to the elaboration of a detailed descriptive system. The SEM descriptive system comprises seven fundamental 
categories: General characteristics (1), Physical reactions and behaviours (2), Perception (3), Cognition (4), Feelings/Emotions (5), Existential and transcendental aspects (6), Personal and social aspects (7). Each of these categories is itself divided into specific subcategories.

While Gabrielsson focuses his definition on the musical experience itself, Becker (2004, p. 45 ) focuses on the experiencing person. She defines as a "deep listener" someone with "the ability to respond with strong emotional arousal to musical stimulation" (or, in other words, the ability to experience a SEM when the relevant musical stimulus is performed). If the arousal is strong enough and if the listener's social background values trancing, this reaction can even lead to a trance. Trance and SEM are both body reactions involving neural stimulations of specific brain areas and resulting in physical reactions (Becker, 2004, pp. 28-29). Therefore, it can be stated that a trance is preceded by a SEM.

It must also be mentioned that many terms can be used to describe inner responses to music: affects, emotion, mood, feeling, arousal, etc. (Sloboda \& Juslin, 2001, p. 75). In this paper, the expression "inner reaction to music" will be used, in order to avoid any confusion.

\section{The Ethiopian lyre bagana}

The bagana is a ten-stringed box-lyre belonging to the musical tradition of the Ethiopian Amhara. Made of wooden pillars and soundbox - except for the soundboard, usually made of cattle skin - with ten cattle gut strings, the bagana is an intimate instrument. Played solely with the singing voice, in order to pray and meditate about one's sins, the bagana is the only melodic instrument played exclusively for religious purposes. The bagana belongs to the zema, the part of the Amhara musical expressions related to the dogma of the Orthodox Ethiopian Church (Tewahido), even though it is not a liturgical instrument (Powne, 1968, p. 56). Its myth of origin explains its religious significance. According to the Amhara oral and written tradition, the bagana is the biblical King David's lyre, who received it from God so he could praise Him with it. The bagana was brought to Ethiopia by Menelik I, son of King Solomon and Queen of Sheba, together with the Ark of Covenant (Tabot) which materialized the election of the Christian Ethiopians as the new Chosen People. King David, ancestor of the Virgin Mary, the mother of Jesus (Mekouria, 1994, p. 146) is important in the Orthodox Ethiopian faith. His psalter (called the Dawit) is committed entirely to memory during the traditional religious training (Shelemay, 1992, pp. 244245) and pious believers recite a psalm every morning (Mekouria, 1994, p. 148).

This status of the bagana as divine gift and biblical instrument explains why the instrument as an artefact is treated with great respect and kept covered with a veil in a special place of the house, an oratory if available, or a corner of a room, often decorated with religious pictures. It is a powerful protector against evil spirits (the devil himself is reputed to back away when he sees it); the sacred character of the bagana can be seen in the strong symbolic relationship between each part of the bagana and major elements of the Ethiopian Orthodox dogma (Weisser, 2007-2008). The soundbox which "gives birth" to sounds symbolizes the Virgin Mary. The ten strings represent the Ten Commandments. The yoke that overlooks the instrument stands for God, who dominates everything, and so on.

As an instrument of God and Kings, the bagana was neither a popular nor a very widespread instrument. In traditional society, players were educated members of the clergy and noblemen and -women. Learning how to play the bagana was part of the traditional education of young nobles, while famous emperors and queens used to be renowned players. Nowadays, after the transmission gap (Aga, 2000, p. 9) caused by the Derg regime (1974-1991), playing the bagana has regained some interest during the last few years. The meaning of the bagana, its very 
existence and its habitus of listening (Becker, 2004, pp. 70-71) is taught to people by members of the Ethiopian Orthodox church in Senebet, the Sunday Schools (Chaillot, 2002, pp. 64-70).

Nowadays, the bagana plays a special role in Amhara society. Considered to be one of the oldest instruments of the planet (Merahi, 2004, pp. 26-27), played with lyrics glorifying old ways of life and the great deeds of famous leaders, the bagana carries strong values of traditionalism and reminiscence. Playing or listening to the bagana is a way to assert oneself as respectful of the traditional values and as being nostalgic for an idealized (although rather imprecise) "glorious past". The way players (especially women) dress up to play the bagana in public is significant. To wear at least one traditional element (netella veil, gabi shawl) is almost mandatory. Whenever they can, players wear a full traditional white outfit (Figure 1).

The playing posture is hieratic, since the body must be engaged a minima in the playing and in the listening, as explained by Alemu Aga (2000), the most famous bagana player currently:

Its special power makes the listener tranquil and concentrate without making any kind of body movements, like with the hands, with the shoulders or with the feet as is done in response to other nonBegenna music. Probably due to the tranquility that is characteristic of the Begenna music, it is said that in order to play the Begenna one must first acquire attitudinal change. (p. 9)

The bagana is an instrument considered to be "different" from others. Its religious and symbolic role is very important in the way the instrument and its performance is perceived (Weisser, 2007-2008).

Like other Amhara instruments, the bagana is always tuned according to a pentatonic modal scale. Scales are not fixed in terms of absolute pitch but rather defined by the intervals separating the degrees. These intervals may vary, depending on the musician and sometimes even the performance. Bagana players generally adopt one of the two following traditional scales (keniet): anchihoye and tezeta. The anchihoye keniet varies little; it is characterized by the alternation of intervals smaller or close to the tempered semitone (intervals 1 and 3 ) and two equal or bigger than the tempered minor third (intervals 2 and 4). The tezeta keniet, in turn, can be played in two different ways. The most common type of tezeta is anhemitonic. The closest tempered intervals used are the major second (intervals 1, 3, and 4), and the minor third (interval 2). These scales seem to possess each a specific ethos: tezeta literally means "nostalgia, reminiscence" and anchihoye is reputed to be "very sentimental" (Alemu Aga, personal communication, 2005).

The bagana is a solo instrument and it may be accompanied by the singing voice only. Like Amhara music in general, bagana songs are repetitive but much more so than pieces played on other instruments. A yebagana mezmour ("bagana [spiritual] song") is made up of a short melody (from about 8 to 30 seconds) repeated many times over (bagana songs can often last more than 10 minutes), but each time with different lyrics except for the refrain (see below). Melodic variation of the ostinato, when it occurs, is always subtle (from a single note to half a musical phrase). Singing voice and bagana are in a relation of quasi-homophony (Weisser, 2005).

Each song always contains a refrain or azmatch ("standing on top", "directing"). This can either be with lyrics or purely instrumental. A song usually begins with a brief instrumental introduction which includes the musical "signature" of the musician and/or the melody to be performed. This derdera serves to prepare the musician physically and emotionally and draws the attention of the listeners (if there are any).

There are two categories of bagana songs: selamta, and varied songs. All selamta songs follow the same melody (see Figure 2). Their azmatch is purely instrumental, and their relatively simple poetic text narrates an episode from the Bible or offers praise to God, to Jesus, or to the Virgin Mary. Selamta are syllabic songs with little vocal ornamentation. Varied songs theoretically 


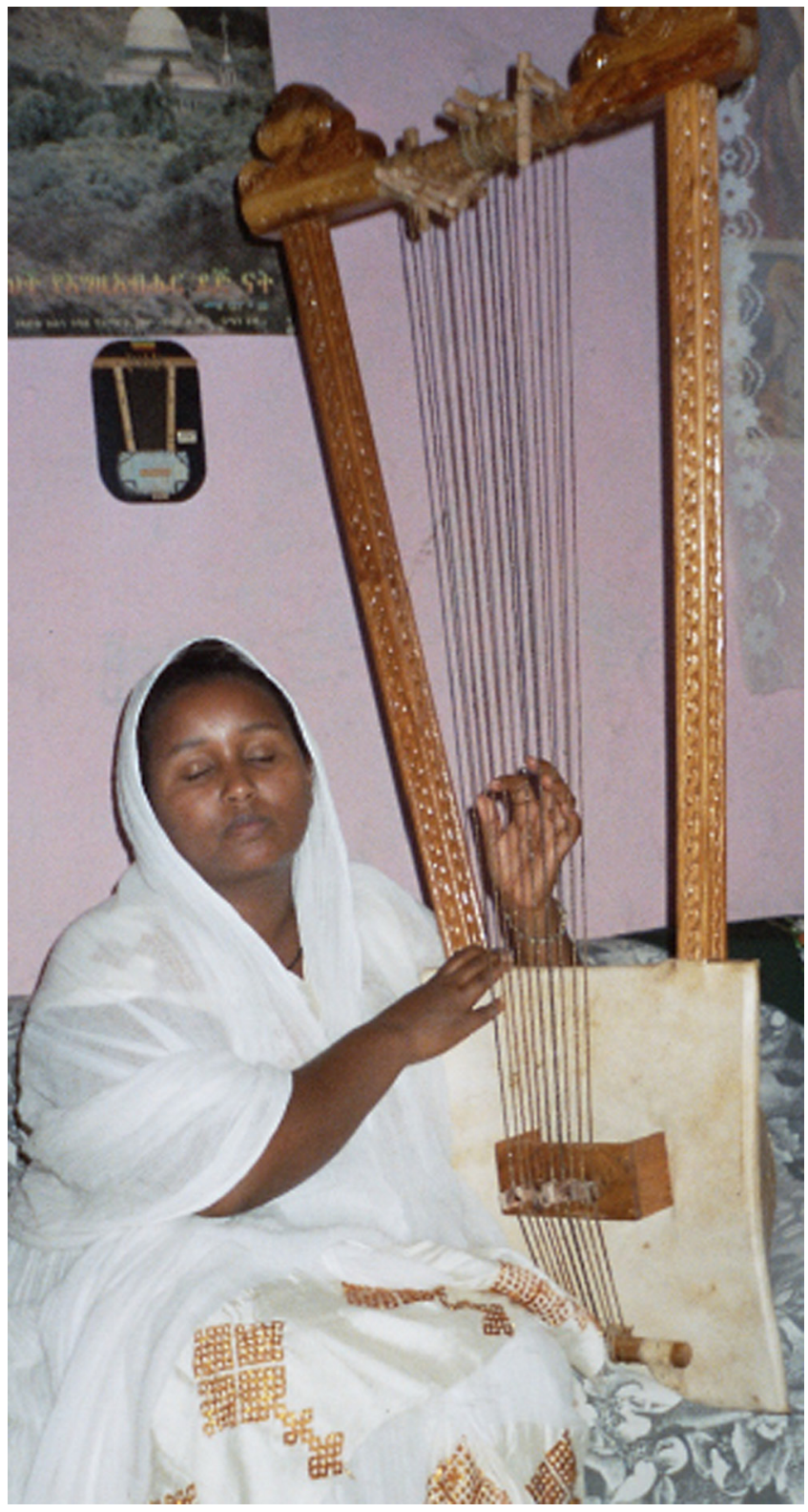

Figure I. Young experienced bagana player wearing the netella (traditional veil) as a sign of respect for the instrument. Musician's house, Addis Ababa, 2005. Photo (C) Stéphanie Weisser.

have a distinct melody each. In practice, however, few new melodies are now composed. Musicians tend to use an existing melody (which they may alter slightly) to which they fit new lyrics. Most often, the lyrics of varied songs contain a series of short poems (q'ene) with no apparent thematic link with each other, and carrying a double meaning. Varied songs may contain little vocal ornamentation. 

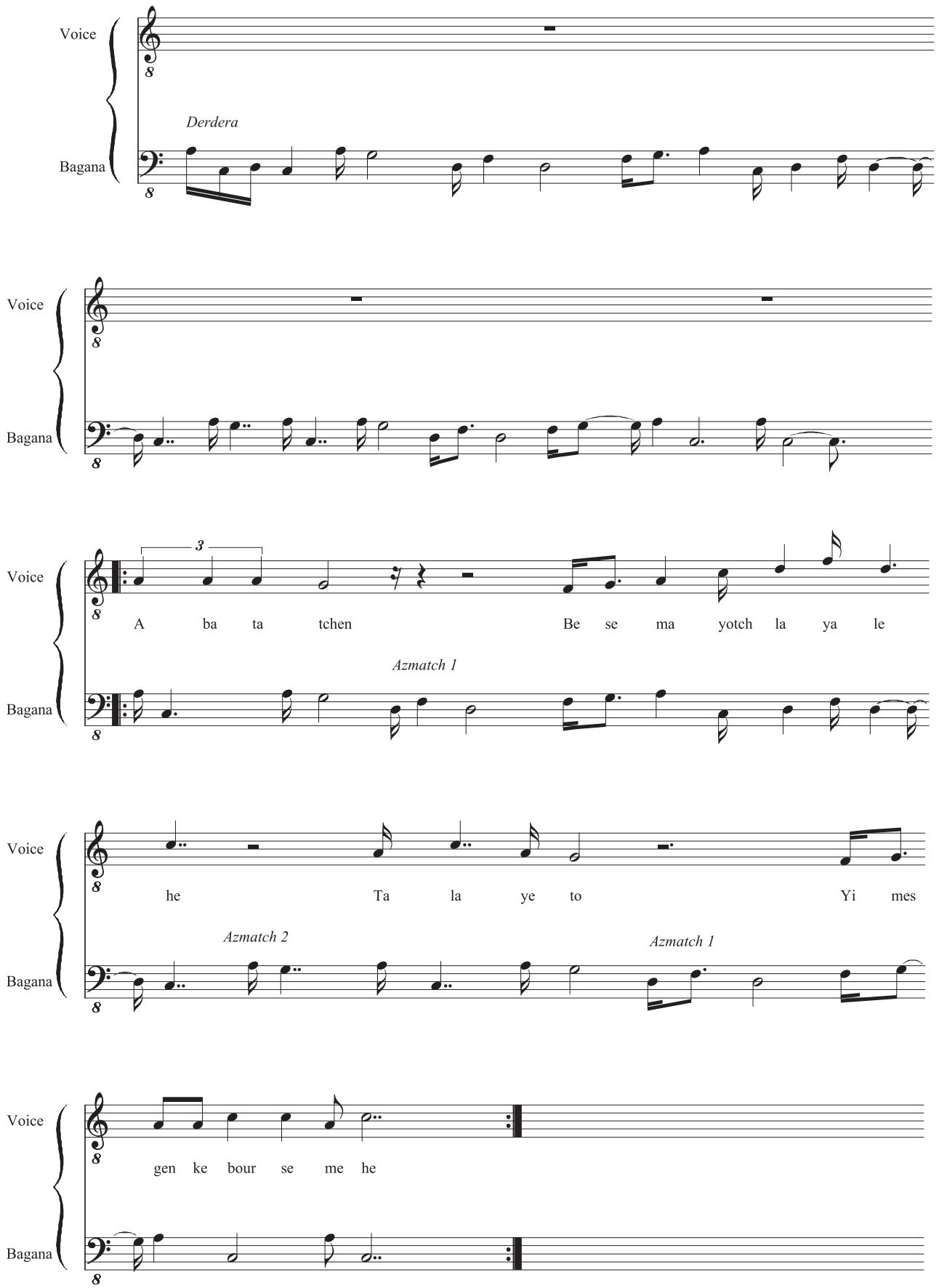

Figure 2. Transcription of the derdera and first presentation of the ostinato of the bagana song Abatatchen Hoy ("Our Father") as played by Alemu Aga in tezeta keniet. Abatatchen Hoy belongs to the selamta songs. 
Bagana songs are characterized by the use of a specific rhythm (Weisser, 2006a). The listener often has the impression of a "moving pulse" (from about 40 pulses/mn to about 100 pulses/ $\mathrm{mn})$. When measured, however, the different ostinato realizations in a song are shown to have the same overall duration: for example, less than $0.5 \mathrm{~s}$ maximal variation was measured for an ostinato of an average duration of 8.5s, repeated 17 times (song duration: 3.40mn). This sensation of a "moving pulse" is due to the use as a reference of a very fast discrete pulsation (from 164 to 190 pulses/mn). The listener perceives only the first of a group of pulses, each group containing a different number of theses discrete pulses (from two to five).

The lyrics of the songs always exhibit a rather elaborate poetic form requiring in-depth religious and historical knowledge. Recurring themes of bagana songs are death, the futility of life on earth and its perversions. The lyrics seem to possess a cathartic dimension: musicians and listeners exorcize the frustrations stemming from the toils of everyday life and the fear of death, giving meaning to their suffering as the path to redemption (Weisser, 2005).

Bagana timbre is one of its most striking characteristics, for western(ized) as well as local listeners. The buzzing of the bagana sounds does not have an equivalent in Amhara culture. The bagana provides very low buzzing sounds (with fundamental frequencies of between 50 and $200 \mathrm{~Hz}$, depending on the tuning and the instrument) thanks to a very simple mechanism. This mechanism comprises a wide wooden bridge and leather stripes placed between each string and the bridge. This mechanism, existing in several string instruments around the world (such as the Indian tanpura, the Kenyan obokano), generates an extra contact point between the upper rim of the bridge and the string. This contact point considerably modifies the vibratory behaviour of the string: the spectrum of the sounds is considerably enriched, and comprises numerous spectral components up to $10 \mathrm{kHz}(1.5 \mathrm{kHz}$ without the mechanism). The attack and decay of the sounds produced with the mechanism are also modified, up to the point that it is sometimes not identified as a plucked instrument by naïve listeners. It has been noted that the behaviour of a string with such a mechanism resembles that of a bowed string (Helmoltz-like motion, cf. Fletcher \& Rossing, 1998, p. 268-269).

The bagana player cannot produce loudness variations and the instrument usually generates relatively weak sounds. Even though the mechanism heightens the global loudness of the sounds by amplifying the energy of the high ranked spectral components, especially those corresponding to the most sensitive area of the human ear (Leipp, 1989, p. 114-116), it also "normalizes" this global loudness. Organological choices explain why the global loudness is relatively weak. The bagana is equipped with thick gut strings (1.9-2.8 mm diameter, depending on the quality), often heterogeneous, and generally has a skin soundboard (which does not radiate sound vibrations as efficiently as wood). Moreover, since the loudness of the sounds decreases with the square of distance away from the instrument, the player experiences very different sensations from a listener.

\section{Method}

This study is based on information collected during four field researches held in Ethiopia, and one in Washington, DC (USA), between 2002 and 2006. The data were collected through informal interviews, discussions and observations.

\section{Participants}

Interviews allowed the collection of statements about the impact of the bagana. Those statements were answers to a direct question: "What do you feel when you play/hear the bagana?" 
This question was asked of 32 voluntary participants. Among these, 19 were players or players in training, one was a singer associated with a bagana player, two were lyric writers and ten were simple listeners. The participants included 10 women and 22 men. Seventeen participants were aged 15-29 years, seven between 30 and 49 years, eight aged 50 or over. Twentyfour of the interviews (18 players, 3 listeners, 2 lyric writers, and 1 singer) were conducted in Addis Ababa, 7 in Ginir (Bale Province, Ethiopia) and one in Washington, DC (USA). About $80 \%$ of the interviews took place after a bagana event (public performance, lesson, recording session). The interviews were conducted in English, with a simultaneous translation into Amharic and vice versa, when needed. Some informants (especially the virtuoso players) were interviewed several times, sometimes years apart. Several informants were interviewed many times (especially the virtuoso and experienced players, see below), others only once.

The players were subdivided into three categories based on their playing abilities and social recognition. Virtuoso players have played the bagana for more than 40 years and have another bagana-related activity (teaching or making). They have also released several audio cassettes or $\mathrm{CD}$, are respected as masters and as stylistic models by young players. They compose their own songs and have an extended and original repertoire. Only two men players can be qualified as such. Experienced players have played for several years, teach or make bagana or are known as players (through releasing of recordings or public performances). Seven men and two women belong to this category. Beginners/amateurs are players in training or those who refuse to perform publicly for various reasons. Eight informants belong to this category (five women and three men).

Some information about the emotional impact of structural features of the bagana was spontaneously given by players during discussions. Five statements of this kind were collected, mostly focused on scales, rhythm, timbre and vocal techniques used in bagana performances. In total, 108 statements were collected.

\section{Procedure}

The analysis of the 108 collected statements was made according to the SEM classification established by Gabrielsson and Lindström Wik (2003). The reliability of all the attributions made was verified by Alf Gabrielsson. The interjudge reliability of the first classification attempt, expressed in terms of the percentage of reactions placed in the same category by both Alf Gabrielsson and myself, was about 70\% agreement. Perfect agreement was reached on the final classification.

Expressive behaviours (cf. Sloboda \& Juslin, 2001, p. 74) were observed by filming performances and audiences in close-up with zoom (the closeness of the camera being sometimes disruptive). Five bagana public performances in various contexts were recorded. Four performances were held a spiritual context: three of them took place during a paraliturgical event (monthly and annual celebrations of a church) and within the church compound (in the open space surrounding the church itself). The fifth spiritual performance was a religious teaching session organized by a Sunday School, and took place in the public hall inside a church compound. Finally, one event, organized by an association of young journalists, had a didactic purpose and took place in a theatre. Four of these five events happened in Addis Ababa and one in Ginir (Bale Province). Among all these events, only the didactic performance and the one organized by the Sunday School were entirely dedicated to the bagana. During the three paraliturgical ceremonies, the bagana performance was only a part of the ceremonies, which included spiritual songs and dances, sermons, and collective prayers. 


\section{Results}

The classification of the 108 statements into SEM categories and subcategories is detailed in Table 1 (with a maximum of three examples of statements for each category/subcategory).

The 108 statements fall into six of the seven SEM categories (see Figure 3). The most frequent explanations about bagana-related feelings belongs to the fifth SEM category labelled

Table I. Classification of statements related to the emotional impact of the bagana according to the SEM descriptive system.

SEM category/subcategory $\quad \begin{aligned} & \text { Number of Examples of statements } \\ & \text { statements }\end{aligned}$

2. Physical reactions and 3
behaviours

\subsection{Physiological reactions $\quad 3$}

3. Perception

3.1. Auditory perception

3.2. Tactile perception
3.8. Musical perception-cognition

4. Cognition

4.3. Loss of control

4.1 Changed attitude

\subsection{Changed attitude/ relation to music}
4.5. Associations, memory, thoughts

4.7 Musical emotion-cognition
"When I play the bagana, I sometimes have tears" "When I hear the bagana, it makes me cry sometimes" "Bagana makes me cry"
6

1 "The voice of the bagana impresses me very much" "When I hear the bagana, I feel the vibrations all over my body"

"The traditional way of dealing with the rhythm in bagana songs attracts people's minds very much" "The bagana produces a low and mellow sound that penetrates deep into the heart"

"The way our fathers used to play the rhythm of the bagana was not regular and that is why it attracted the mind very much"

"The bagana makes me go deep into my feelings" "It took my mind"

"It penetrates deep into the heart"

"Bagana makes me focused"

"When they hear the bagana, people become devotioned (sic)"

"Bagana attracts people's attention"

To hear the bagana is to hear a lesson"

"The bagana has a message to teach to people"

"When I play, my body is totally immersed into the sound"

"It remembers me of my (deceased) father"

"It remembers me of an old man who played in the church when I was a child"

"It is so beautiful"

"the scale tezeta helps to produce a melancholic effect and the scale anchihoye is very sentimental" 
Table I. (Continued)

SEM category/subcategory $\quad \begin{aligned} & \text { Number of Examples of statements } \\ & \text { statements }\end{aligned}$

5. Feelings/emotions 36

5.2. Positive emotions

26 "I feel happy"

"I feel satisfied"

"I feel appeased"

5.3. Negative emotions

9

"I feel loneliness"

"I feel sad"

"I feel melancholic"

5.4. Different emotions 1

"I feel between sadness and happiness"

6. Existential and transcendental 31 aspects

6.3. Religious experience 31

6.3.1. General religious experience 6

6.3.2. Vision of heaven/God 1

6.3.5. Spiritual peace/harmony 1

6.3.6. Contact/meeting with 7 the divine/the sacred, religious confirmation

\subsubsection{Seek/get in contact} with God

\subsubsection{Music expresses a religious message}

7. Personal and social aspects

7.1. New possibilities, insights, needs

7.2 Music: new possibilities, insights, needs
11

8

3
"When I see a bagana, it is like seeing Almighty God"

"The bagana makes me happy because of my faith"

"When I listen to the bagana, I have the love of God"

"Playing the bagana makes me close to God and the saints/makes my spirit in touch with God"

"The bagana is miraculous"

"The bagana lets you talk to God in peace"

"Playing the bagana is like praying"

"The bagana makes me ready for my confession"

"The bagana reminds me of Christ/King David/the Virgin Mary"

"It makes me think about God"

"The bagana is the only instrument God can be praised with"

"The bagana helps me when I'm angry or depressed"

"When I hear the bagana, I feel free from problems and worries"

"Playing the bagana makes me forget the pain"

"I want to play the bagana every day"

"I will continue to listen to the bagana"

"After I heard the bagana, I left everything to learn how

to play and how to make the instrument"

"Feelings/Emotions" (36 statements, 33\% of the total number of the statements). This category gathers statements in which emotions, feelings, or moods are the most striking element felt by the informants.

The sixth SEM category "Existential/Transcendental aspects" gathers statements dealing with various aspects of the meaning of life, altered states of consciousness and religious experimenting. All of the 31 statements (29\% of the total) in this category fall into the "Religious experience" subcategory (6.3). Within this subcategory, a further subdivision may be operated 


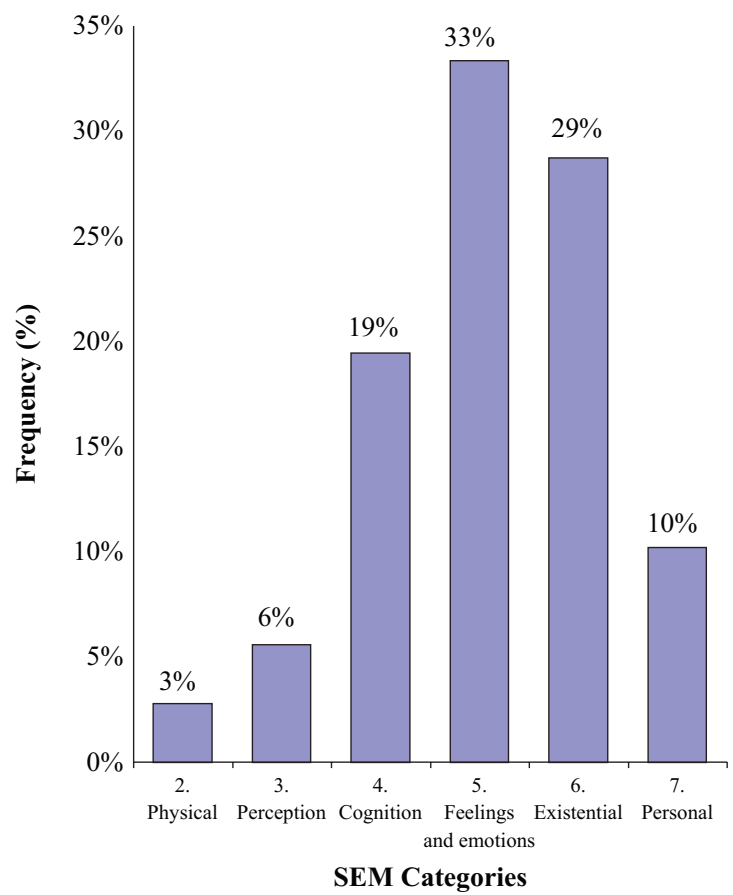

Figure 3. Frequency distribution of the bagana-related statements classified into the SEM categories.

(Figure 4). A small majority of the statements (9) belong to the 6.3.10 subcategory "Music expresses a religious message". There are seven statements in each of the next two subcategories, "Seek/get in contact with God" (6.3.8) and "Contact/meeting with the divine/the sacred, religious confirmation" (6.3.6). There are six statements in the "General religious experience" (6.3.1) subcategory. Finally, two subcategories are represented by one statement only: the "Vision of heaven/God" (6.3.2) subcategory and the "Spiritual peace/harmony" subcategory (6.3.5).

The fourth SEM category "Cognition" deals with statements concerning changes in the perception and the processing of the music, associations, memory, thoughts, and imagery aroused by the music, and description of musical qualities. This category comprises 21 statements (19\% of the total), which can be classified into five of the seven existing subcategories. Nine statements fall into the "Loss of Control" subcategory (4.3). There are four statements each in subcategory 4.1, "Changed Attitude", and 4.4, "Changed attitude/relation to music". There are two statements each in subcategory 4.5, "Associations, memory, thoughts", and 4.7, "Musical emotion-cognition”.

The seventh SEM category is the "Personal and social aspects" and focuses on the social and personal consequences of the musical reactions. Eleven statements (10\% of the total) fall into that category. Among them, eight belong to subcategory 7.1, "New Possibilities, insights, needs". Three statements belong to subcategory 7.2 "Music: New possibilities, insights, needs".

The third SEM "Perception" category gathers subcategories related to sense modalities, to synaesthesia, intensified sensations, multimodal perception and musical qualities. Six 


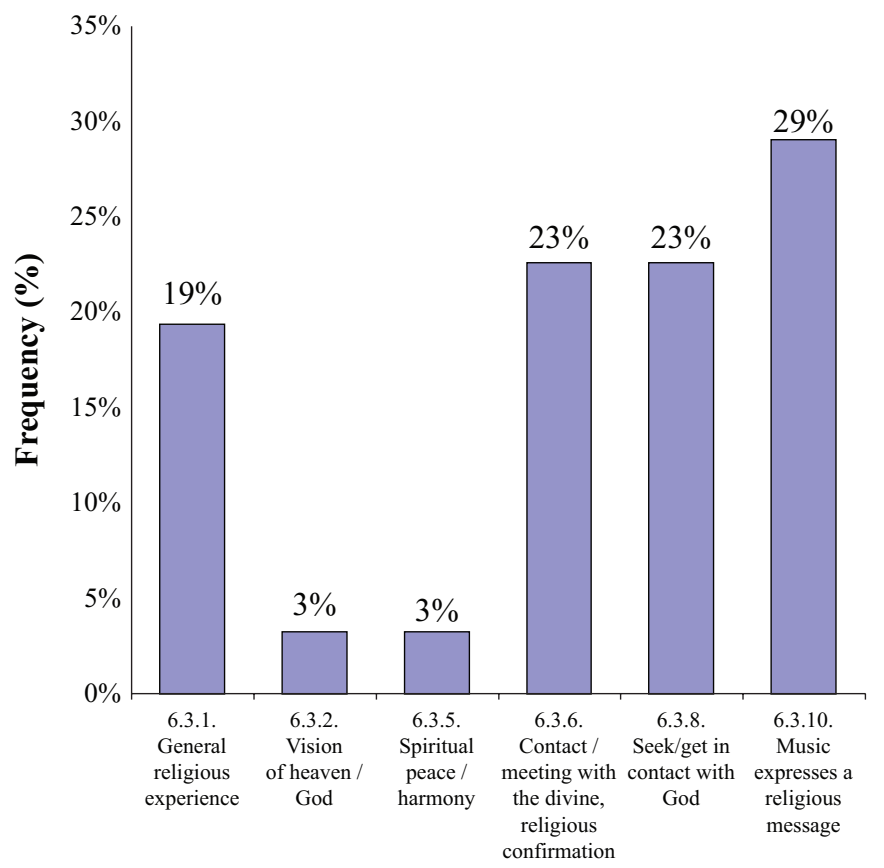

Subdivisions of the 6.3 Subcategory "Religious experience"

Figure 4. Frequency distribution of the bagana-related statements classified in the Religious experience (6.3) SEM subcategory.

statements ( $6 \%$ of the total) fall into this category, and these can be further classified into three of the seven existing subcategories. Four of the five statements collected through discussion fall into that category, more specifically in the 3.8 "Musical perception-cognition" subcategory since they focus on qualities of the music. There is one statement each in subcategory 3.3, "Tactile perceptions", and 3.1, "Auditory perception".

The least represented SEM category is the second, "Physical reactions and Behaviours". This category gathers statements focusing on physiological reactions, behaviours, and quasi-physical reactions. Only three statements fall into this category ( $3 \%$ of the total), all of them belonging to subcategory 7.1, "Physiological reactions".

Analysis of the behaviour of players and listeners during public performances shows that the physical reactions provoked by a bagana performance are minimal. The implicit "rules" of posture of bagana playing are always respected. The playing is never staged or demonstrative. Physical immobility is required, as well as impassiveness of the face; only the fingers and sometimes the head are allowed to move. There is no attempt to convey emotions by means other than the musical sounds themselves (not even through eye contact with the audience). The observable reaction in the listeners is an immediate calming, even if the degree of excitement is maximal just a few seconds before the bagana performance starts. Most of those attending such a performance present a sad, focused, and sometimes overwhelmed face (see Figure 5). It is not uncommon to see people crying when listening to the instrument, sometimes as early as after a few seconds of playing, before the lyrics (carrying the meaning of the song) have even started. 


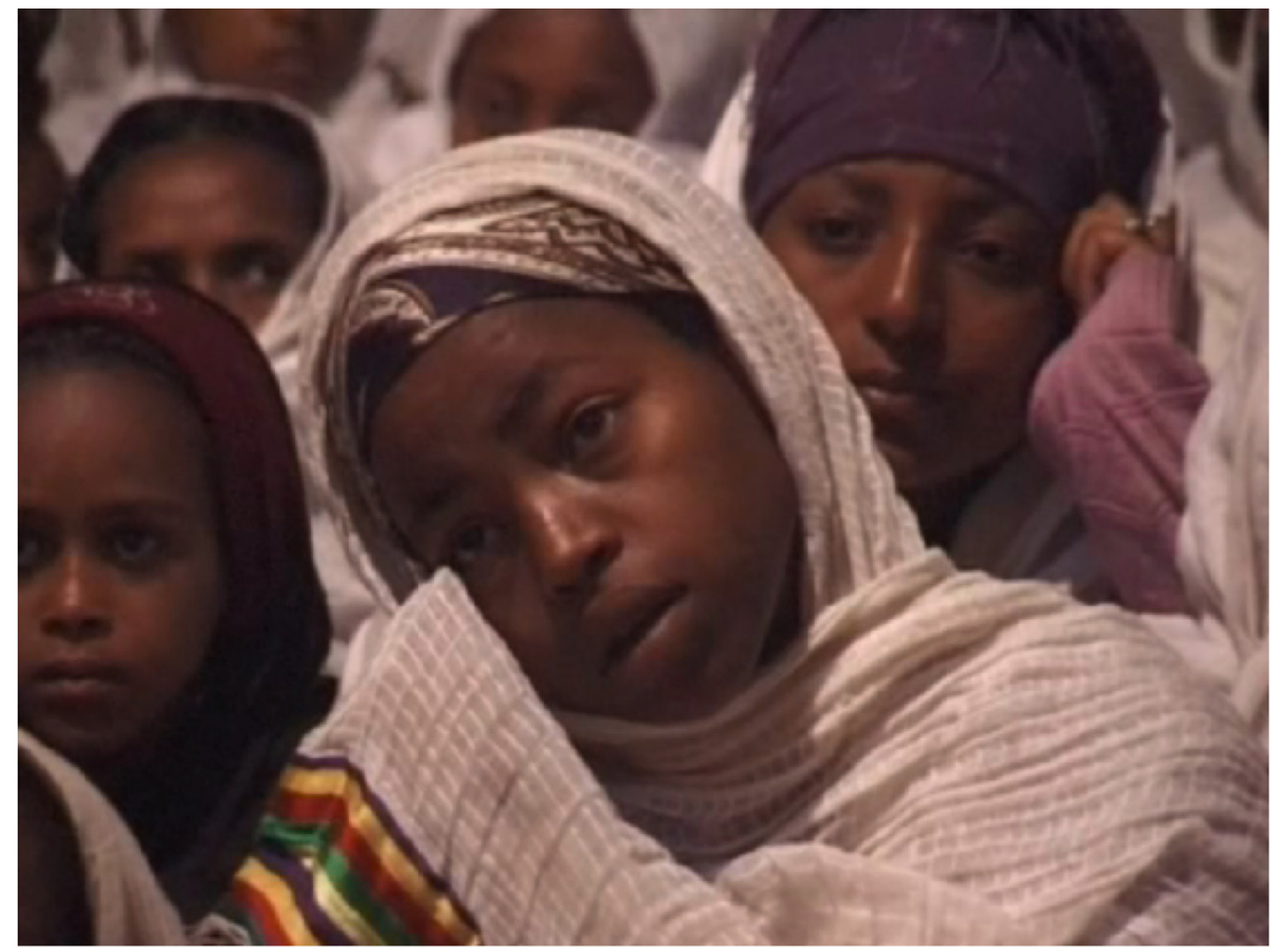

Figure 5. Young girl listening to a public bagana performance. Kiddus Raguél Church,Addis Ababa, December 2002. Photo (C) Stéphanie Weisser.

When the performance of the bagana is considered to be religious (as in paraliturgical ceremonies or a Sunday School event), the audience does not applaud and pronounces conventional words of gratitude ("May God give it back to you"). When it is played for a didactic purpose or when the performance is not in an Ethiopian Orthodox Christian Church, the audience may (and usually do) applaud, and they do not pronounce the gratitude formula. The evaluation of the religious or didactic nature of the event was in every situation correctly performed by the audience.

\section{Discussion}

This investigation shows that the majority of the statements (36 statements, 33\%) belong to the fifth category (Feelings/emotions), followed by the Category 6, Existential and transcendental aspects (31 statements, 29\%). At the subcategory level, the order is reversed: statements falling in the Religious experience subcategory (6.3) are more numerous (31) than those falling into the 5.2 Positive emotions subcategory (26). This shows that players and listeners acknowledge first the religious and emotional impact of the bagana, regardless of age, gender, or experience. On the other hand, the reactions least commonly admitted to are related to physical behaviours. This result can be explained by the social conventions about decency and the general conception of the body in Christian Amhara society. Since the human body is considered 
weak, it causes most of the sins that jeopardize the eternal life of the soul. When asked about their feelings, both listeners and players often point out their state of mind, and not their "state of body", especially within a religious context.

A great number of statements (26) fall into the Positive emotions subcategory (5.2) as compared to the Negative (5.3) or Different (5.4) subcategories (9 and 1 statements respectively). These results seem to contradict the observations of overwhelmed faces and tears during performances, but they actually support the hypothesis of a cathartic function of the bagana performance: since the statements were mostly collected after a bagana performance, it is plausible to assume that participants were describing their inner state after the performance is completed, and not the reactions throughout the performance.

The great number of statements falling into subcategories 6.3.6 and 6.3.8 (both related to the contact with the divine) can also be explained by the conception of God in Christian Amhara society: the sacred has to remain hidden and may not be investigated - as illustrated by the lyrics of the famous bagana song Manimeramere ("Who can question?", cf. Weisser, 2005, p. 4547 , 288). God himself is usually elusive (Reminick, 1975, p. 28) and can only be "reached" through intercessors, the most important being the Virgin Mary, to which the bagana is strongly linked according to tradition. King David appeared beside her deathbed to ease her death by playing the bagana and iconographical representations of this event are frequent (Weisser, 2007-2008).

The bagana seems to activate some strong cognitive associations and it seems to do so by itself. No contextual details were spontaneously given by the informants: time, place, songs, performers, style, live or recorded performance, and so on, do not seem to have much influence on the reactions the instrument creates. Several factors explain this fact: first, the implicit structural features of bagana playing style are largely respected by most players. The differences between playing styles, songs, and so on are thus rather minimal. Second, as noted before, the sacred remains hidden in Amhara culture. In the end, for non-specialist listeners, the strong cognitively-constructed identity of bagana surpasses most judgments about structural or contextual features (Scherer \& Zentner, 2001, pp. 362-365).

The contribution of the formal characteristics of the music is explicitly acknowledged by experienced and virtuoso players only. As there were only a handful of these (9 experienced players and 2 virtuoso players), a study based on judgments of experts, such as the one conducted by Scherer, Zentner and Schacht (2001-2002) would not be relevant. An investigation of the causal links between musical features and emotion perception/reaction would require digital manipulations of these features (Scherer, Zentner, \& Schacht, 2001-2002, p. 153), even though the loss of musical coherence caused by the manipulations has already been shown to be problematic for similar trials (Weisser, unpublished field notes, 2004).

Nevertheless, it can be assumed that musical characteristics are a far from negligible factor in the elicitation of emotional reactions by bagana performances. The structural features of this repertoire probably concur with its cognitively-constructed identity in order to produce specific reactions (Weisser, 2006b). The simplicity and repetitiveness of the melodic construction, the use of modes with a specific ethos, the ambiguous rhythm, the absence of dynamic changes, the limited loudness and the very specific instrumental and vocal timbres most probably facilitate the identification of the instrument and the activation of the cognitive associations. The words by Berliner (1981) about the Shona mbira can be applied almost verbatim to the bagana: "The . . - player, enveloped by the sound of the music, entranced by its repetitive, cyclical nature, and captivated by its subtle variations, may find his state of consciousness transformed" (p. 131).

The SEM descriptive system has proved helpful for the analysis of the inner reactions induced by bagana performances, in that it provided a detailed description of the nature of the 
components of what is felt during a bagana experience, as well as the respective importance of these components. It shows that, even in the case of a very specific repertoire strongly linked with specific meanings and performance conditions such as the bagana, the range of inner reactions aroused is quite varied. Because it uses free descriptions, the SEM system avoids the use of predetermined affect terms, which "may be not suited to capture the essence of musically evoked emotions” (Zentner, Grandjean, \& Scherer, 2008, p. 495), especially in a socio-cultural context where emotion studies are still scarce. The SEM descriptive system also allows the inclusion of both contextual and personal dimensions of a performance, which are in this case of great importance regarding the inner reactions elicited by the bagana.

Nevertheless, some difficulties were encountered using the SEM descriptive system: the number of categories and subcategories requires a great number of statements in order to provide valid statistical results. When further divisions are to be operated (such as by age, gender or experience), the number of statements becomes even more critical. The issue of the reliability of the attributions (especially in a cross-cultural situation such as this one) also raises questions. And finally, using the SEM descriptive system requires training, as noted by Gabrielsson and Lindström Wik (2003).

The SEM descriptive system is useful in investigating inner reactions to $a$ specific music, even though those reactions are not "strong". Statements can be gathered informally, whether in response to a direct question or spontaneously during discussion. For ethnomusicologists, the SEM system can be a precious tool for quantifying and describing in a systematic way the nature of the inner reactions they encounter, and then be a very first step to a more in-depth study of these reactions. Moreover, it could also be a very valuable methodological framework in the evaluation of the way a repertoire is conceptualized, a question of crucial importance in ethnomusicology.

\section{Acknowledgements}

I would like to express my profound gratitude to all the Ethiopian participants and to Prof. Irène Deliège, Prof. Daniel Holender and Prof. Alf Gabrielsson for their help and valuable insights and observations. The field researches were supported by the Fonds National de la Recherche Scientifique (Belgium) and the UNESCO Norway/Trust-in-Fund Project "Ethiopia: Traditional music, dance and instruments. A Systematic Survey". Many thanks also to Mrs Dominique Lemaire for the proofreading and corrections.

\section{References}

Aga, A. (2000). The Begenna: A Unique Cultural Heritage. Institute of Ethiopian Studies Bulletin, 21-22, $5-12$.

Aubert, L. (2005). La voix des ancêtres : Notes sur l'usage de la musique dans les sociétés traditionnelles. Connaissance des Religions, 75-76, 203-214.

Becker, J. (2001). Anthropological perspectives on music and emotion. In P. N. Juslin \& J. A. Sloboda (Eds.), Music and emotion: Theory and research (pp. 135-160). Oxford: Oxford University Press.

Becker, J. (2004). Deep listeners: Music, emotion and trancing. Bloomington and Indianapolis: Indiana University Press.

Berliner, P. (1981). The soul of Mbira: Music and traditions of the Shona people of Zimbabwe. Chicago and London: University of Chicago Press.

Chaillot, C. (2002). The Ethiopian Orthodox Tewahedo church tradition: A brief introduction to its life and spirituality. Paris: Inter-Orthodox Dialogue.

Damasio, A. (2003). Looking for Spinoza: Joy, sorrow and the feeling brain. New York: Harcourt.

Fletcher, N. H., \& Rossing, T. D. (1998). The physics of musical instruments (2nd ed.). New York: Springer.

Gabrielsson, A. (2001). Emotions in strong experiences with music. In P. N. Juslin \& J. A. Sloboda (Eds.), Music and emotion: Theory and research (pp. 431-449). Oxford: Oxford University Press. 
Gabrielsson, A., \& Lindström Wik, S. (2003). Strong experiences related to music: A descriptive system. Musicae Scientiae, 7(2), 157-217.

Leipp, E. (1989). Acoustique et musique (4th ed.). Paris: Masson.

Mekouria, T. T. (1994). L'influence du roi David et de son Psautier en Ethiopie. In C. Lepage et al. (Eds)., Actes de la Xème Conférence Internationale des Etudes Ethiopiennes (1988) (pp. 145-153). Paris: Société Française pour les Etudes Ethiopiennes.

Merahi, K. K. (2004). The most versatile Ethiopian scholar, St. Yared and his outstanding work. Addis Ababa: The Author.

Merriam, A. P. (1964). The anthropology of music. Evanston, IL: Northwestern University Press.

Nattiez, J. J. (1981). Paroles d'informateurs et propos de musiciens: Quelques remarques sur la place du discours dans la connaissance de la musique. Yearbook for Traditional Music, 13, 48-59.

Nattiez, J. J. (2005). Musiques traditionnelles et significations. In J. J. Nattiez (Ed.), Musiques: Une encyclopédie pour le XXIe siècle (Vol. 3 : Musiques et cultures, pp. 971-991). Arles: Actes-Sud, 2003. Paris: Cité de la musique.

Ortony, A., Clore, G. L., \& Collins, A. (1988). The cognitive structure of emotions. Cambridge: Cambridge University Press.

Powne, M. (1968). Ethiopian music: An introduction. A survey of ecclesiastical and secular Ethiopian music and instruments. London/New York/Toronto: Oxford University Press.

Reminick, R. A. (1975). The structure and functions of religious belief among the Amhara of Ethiopia. In H. G. Marcus (Ed.), Proceedings of the First U. S. Conference on Ethiopian Studies (1973) (pp. 25-42). East Lansing, MI: African Studies Center, Michigan State University.

Rickard, N. S. (2004). Intense emotional responses to music: A test of physiological arousal hypothesis. Psychology of Music, 32(4), 371-388.

Rouget, G. (1990). La musique et la transe: Esquisse d'une théorie générale des relations de la musique et de la possession. Paris: Gallimard.

Scherer, K. R., \& Zentner, M. R. (2001). Emotional effects of music: Production rules. In P. N. Juslin \& J. A. Sloboda (Eds.), Music and emotion: Theory and research (pp. 361-392). Oxford: Oxford University Press.

Scherer, K. R., Zentner, M. R., \& Schacht, A. (2001-2002). Emotional states generated by music: An exploratory study of music experts [Special issue]. Musicae Scientiae, 2001-2002, 149-171.

Shelemay, K. K. (1992). The musician and transmission of religious tradition: The multiples roles of the Ethiopian Däbtära. Journal of Religion in Africa, 22(3), 242-260.

Sloboda, J. A., \& Juslin, P. N. (2001). Psychological perspectives on musical emotions. In P. N. Juslin \& J. A. Sloboda (Eds.), Music and emotion: Theory and research (pp. 71-104). Oxford: Oxford University Press.

Weisser, S. (2005). Etude ethnomusicologique du bagana, lyre d'Ethiopie. Unpublished PhDThesis in Musicology, Université Libre de Bruxelles (Belgium).

Weisser, S. (2006a). Transcrire pour vérifier: le rythme des chants de bagana d'Ethiopie. Musurgia, 13(2), 51-61.

Weisser, S. (2006b). The Ethiopian lyre bagana: An instrument for emotion. In M. Baroni, A. R. Addessi, R. Caterina, \& M. Costa (Eds.), Proceedings of the 9th International Conference on Music Perception and Cognition (pp. 376-382). Bologna: ICMPC-ESCOM.

Weisser, S. (2007-2008). Le bagana, instrument de musique et de prière Amhara. Annales d'Ethiopie, 23, 61-76.

Zentner, M. R., Grandjean, D., \& Scherer, K. R. (2008). Emotions evoked by the sound of music: Characterization, classification, and measurement. Emotion, 8(4), 494-521. 